\title{
GAT 2-Transkriptionskonventionen
}

\author{
[ ] \\ ${ }^{\circ} \mathrm{h} / \mathrm{h}{ }^{\circ}$ \\ ${ }^{\circ} \mathrm{hh} / \mathrm{hh}^{\circ}$ \\ ${ }^{\circ}$ hhh / hhh ${ }^{\circ}$ \\ (.) \\ $(-)$ \\ ? \\ , \\ $-$ \\ ; \\ und_äh \\ äh öh äm \\ haha hehe hihi \\ ((hustet)) \\ $\ll$ lachend $>>$ \\ $\ll:-)>$ soo $>$ \\ $\mathrm{hm}$ ja nein nee \\ hm_hm ja_a nei_ein nee_e \\ Phm?hm, \\ $(x x x),(x x x x x x)$ \\ (solche) \\ (also/alo) \\ ((unverständlich, ca. 3 \\ Sek)) \\ $((.)$. \\ $\rightarrow$ \\ $=$ \\ : \\ $::$ \\ $:::$ \\ ? \\ akZENT \\ akzEnt \\ ak! ZENT! \\ $\uparrow \downarrow$ \\ $\ll f(f)\rangle>$ \\ $\ll p(p)>>$ \\ $\ll$ len $>>$ \\ $\ll h>>$ \\ Überlappungen und Simultansprechen \\ Ein- bzw. Ausatmen von ca. 0.2-0.5 Sek. Dauer \\ Ein- bzw. Ausatmen von ca. 0.5-0.8 Sek. Dauer \\ Ein- bzw. Ausatmen von ca. 0.8-1.0 Sek. Dauer \\ Mikropause (bis ca. 0.2 Sek.) \\ kurze Pause (bis ca. 0.5 Sek.) \\ Pause in Sekunden (gemessen) \\ Tonhöhenbewegung: hoch steigend \\ Tonhöhenbewegung: mittel steigend \\ Tonhöhenbewegung: gleichbleibend \\ Tonhöhenbewegung: mittel fallend \\ Tonhöhenbewegung: tief fallend \\ Verschleifungen innerhalb von Einheiten \\ Verzögerungssignale, sog. „gefüllte Pausen“ \\ silbisches Lachen \\ Para- und außersprachliche Handlungen (sofern kein \\ multimodales Display) \\ Sprachbegleitende para- und außersprachliche Ereignisse (mit \\ Angabe der Reichweite) \\ "smile voice“" \\ einsilbige Rezeptionssignale \\ zweisilbige Rezeptionssignale \\ mit Glottalverschlüssen, meistens verneinend \\ ein bzw. zwei unverständliche Silben \\ vermuteter Wortlaut \\ mögliche Alternativen \\ unverständliche Passage mit Angabe der Dauer \\ Auslassung im Transkript \\ Verweis auf im Text behandelte Transkriptzeile \\ schneller Anschluss \\ Dehnung, Längung (ca. 0.2 Sek.-0.5 Sek.) \\ Dehnung, Längung (ca. 0.5-0.8 Sek.) \\ Dehnung, Längung (ca. 0.8-1.0 Sek.) \\ Abbruch durch Glottalverschluss \\ Fokusakzent \\ Nebenakzent \\ extra starker Akzent \\ auffälliger Tonhöhensprung (nach oben/nach unten) \\ laut/sehr laut (mit Angabe der Reichweite) \\ leise/sehr leise (mit Angabe der Reichweite) \\ langsam (mit Angabe der Reichweite) \\ hohes Tonhöhenregister (mit Angabe der Reichweite)
}

๑ Open Access. ( 2021 Heike Knerich et al., publiziert von De Gruyter. (c) BY-NC-ND Dieses Werk ist lizenziert unter einer Creative Commons Namensnennung - Nicht-kommerziell - Keine Bearbeitung 4.0 International Lizenz. https://doi.org/10.1515/9783110688696-029 
Weiterführende Hinweise in:

Selting, Margret, Peter Auer \& Dagmar Barth-Weingarten et al. (2009): Gesprächsanalytisches Transkriptionssystem 2 (GAT 2). Gesprächsforschung - Online-Zeitschrift zur verbalen Interaktion 10, 353-402. Im Internet unter: http://www.gespraechsforschung-online.de/fileadmin/da teien/heft2009/px-gat2.pdf (Stand: 8.8.2021). 